\title{
Cartilage Thickness and Cyst Volume Are Unchanged 10 Years After Periacetabular Osteotomy in Patients Without Hip Symptoms
}

\author{
Inger Mechlenburg PhD, Jens Randel Nyengaard DMSc, \\ John Gelineck MD, Kjeld Soballe DMSc
}

Received: 2 November 2014/ Accepted: 19 March 2015/Published online: 31 March 2015

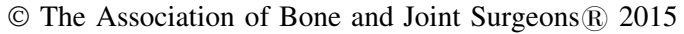

\begin{abstract}
Background Periacetabular osteotomy (PAO) may affect cartilage thickness and cyst volume in patients with hip dysplasia. However, as no studies randomizing patients to either PAO or conservative treatment have been performed, to our knowledge, it is unknown if PAO directly affects the development or progression of osteoarthritis in patients with hip dysplasia.

Questions/purposes We investigated (1) changes of cartilage thickness in the hip after PAO; (2) how many patients had subchondral bone cysts in the acetabulum or

The institution of one or more of the authors (IM, JRN) has received, during the study period, funding from the Danish Rheumatism Association (Gentofte, Denmark), the Bevica Foundation (Copenhagen, Denmark), Oda and Hans Svenningsen Foundation (Copenhagen, Denmark) and the Villum Foundation (Soborg, Denmark).

Each author certifies that he or she, or a member of his or her immediate family, has no funding or commercial associations (eg, consultancies, stock ownership, equity interest, patent/licensing arrangements, etc) that might pose a conflict of interest in connection with the submitted article."

All ICMJE Conflict of Interest Forms for authors and Clinical Orthopaedics and Related Research ${ }^{\circledR}$ editors and board members are on file with the publication and can be viewed on request.

Each author certifies that his or her institution approved the human protocol for this investigation, that all investigations were conducted in conformity with ethical principles of research, and that informed consent for participation in the study was obtained.
\end{abstract}

I. Mechlenburg ( $₫)$, K. Soballe

Department of Orthopaedic Surgery, Aarhus University

Hospital, Tage Hansens Gade 2, 8000 Aarhus C, Denmark

e-mail: Inger.mechlenburg@au.dk; inger.mechlenburg@ki.au.dk

I. Mechlenburg

Department of Clinical Medicine, Aarhus University, Aarhus,

Denmark femoral head; (3) changes in cyst volume; and (4) patients' hip function and pain after PAO.

Patients and Methods In this prospective study, 26 patients (22 women and four men) with hip dysplasia were enrolled with the goal of having MRI of the hip before undergoing PAO and again at 1, 21/2, and 10 years after PAO. Of the 26 patients, $17(65 \%)$ underwent complete followup 10 years after PAO, whereas nine could not be included. Of those nine, three had undergone THA, three had substantial hip symptoms, and three were lost to followup. Thickness of acetabular and femoral cartilage and volume of subchondral bone cysts were estimated in the remaining 17 patients. Ten years postoperatively, the patients' Hip disability and Osteoarthritis Outcome Scores (HOOS) were collected.

Results Preoperatively, the mean thickness of the acetabular cartilage was $1.38 \pm 0.14 \mathrm{~mm}$ compared with $1.43 \pm 0.07 \mathrm{~mm} 10$ years postoperatively $(\mathrm{p}=0.73)$. The mean thickness of the femoral cartilage preoperatively was $1.37 \pm 0.20 \mathrm{~mm}$ compared with $1.30 \pm 0.07 \mathrm{~mm} 10$ years postoperatively $(\mathrm{p}=0.24)$. Seven patients had an increase in cyst volume, six had a decrease, and four had no cysts to start with and remained without cysts. Preoperatively, the median total cyst volume per patient was $6.0 \mathrm{~cm}^{3}$ (range, 1.6-188.3 $\mathrm{cm}^{3}$ ) compared with $2.9 \mathrm{~cm}^{3}$ (range, 0.7$\left.8.2 \mathrm{~cm}^{3}\right)(\mathrm{p}=0.18)$ at 10 years followup. At 10 years, the mean subscores for the HOOS were: pain, $79 \pm 16$;

J. Gelineck

Department of Radiology, Aarhus University Hospital, Aarhus, Denmark

J. R. Nyengaard

Stereology and Electron Microscopy Laboratory and CSGB,

Aarhus University, Aarhus, Denmark 
symptoms, $73 \pm 17$; activities of daily living, $85 \pm 14$; sport/recreation, $68 \pm 22$; and quality of life, $61 \pm 19$.

Conclusions Ten years after PAO, approximately $25 \%$ of the patients who have the procedure will have substantial hip pain and/or undergo hip arthroplasty. Of the patients who do not have substantial hip pain or an arthroplasty, cartilage thickness appears to be preserved. Future studies are needed to help us decide which patients are most likely to succeed with PAO at long-term followup.

Level of evidence Level II, therapeutic study.

\section{Introduction}

Transsartorial periacetabular osteotomy (PAO) [24] is performed in young patients with hip dysplasia to relieve hip pain and increase hip-related physical function [5, 6]. Use of PAO may help postpone or prevent hip osteoarthritis (OA), but to our knowledge, no studies randomizing patients to either PAO or conservative treatment have been done, therefore we do not know whether PAO directly affects the development or progression of OA in patients with hip dysplasia.

Joint space narrowing is a strong radiographic indicator of degenerative changes associated with hip OA [8,9], but the progression of hip OA also can be monitored by changes in cartilage thickness and size of subchondral bone cysts $[14,16]$. Subchondral bone cysts can be caused by pressure on the cartilage and the subchondral bone, which causes the joint fluid to leak into the bone. The swelling and inflammation associated with OA can put extra pressure on the cartilage. With PAO, the biologic hip is preserved and subchondral bone becomes capable of regeneration $[14,17]$, but it is unclear whether the cartilage is able to regenerate.

We asked if cartilage thickness and cyst volume changed during the 10 years after PAO and how patients described their hip pain and function 10 years after that procedure. Specifically, we investigated (1) if changes in hip cartilage thickness occurred after PAO, (2) how many patients had acetabular or femoral head cysts before undergoing PAO, (3) changes in cyst volume in the years after PAO, and (4) patient-assessed hip function and pain after PAO.

\section{Methods}

We performed a prospective cohort study with a 10 -year followup. Our study included 26 patients (22 women and four men) with hip dysplasia scheduled for PAO between April 2003 and June 2004 at our institution. Eighty-six

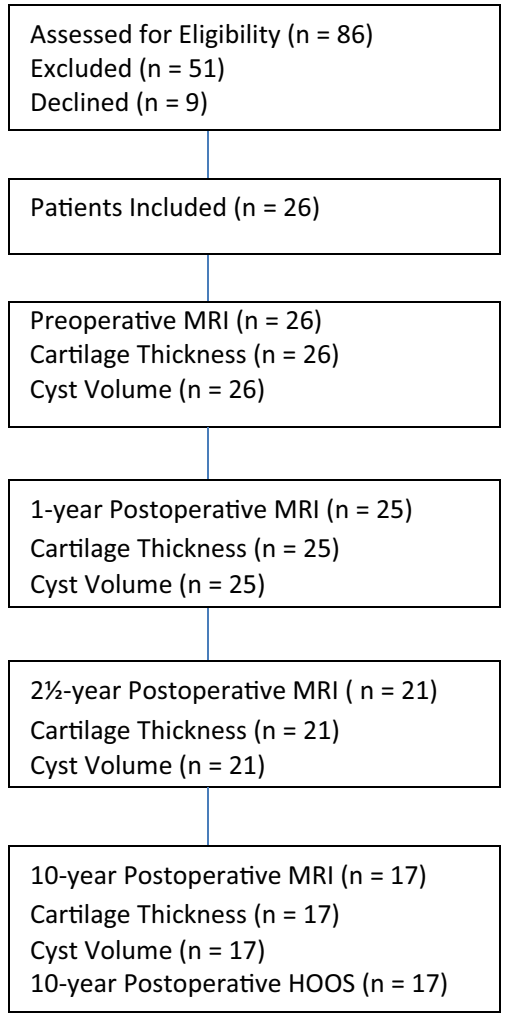

Fig. 1 Twenty-six patients with hip dysplasia scheduled for PAO were included in the study. Patients were seen at our institution between April 2003 and June 2004. HOOS = Hip disability and Osteoarthritis Outcome Scores.

patients with hip dysplasia were assessed for eligibility in the study. Nine patients declined to participate and 51 were excluded. Of those excluded, 11 had a THA and three had an intertrochanteric femoral osteotomy simultaneous with the PAO (Fig. 1).

The median age of the study patients at the time of PAO was 39 years (range, 19-53 years). Study inclusion criteria were: center-edge angle of Wiberg [26] $24^{\circ}$ or less; OA degree, 0 or 1 , according to the classification of Tönnis [25]; spherical femoral heads; closed growth zones in the pelvis; painful hip; and minimum $110^{\circ}$ flexion in the hip. Exclusion criteria were: metal implants, neurologic illnesses, Legg-Calvé-Perthes disease, or previous corrective pediatric hip surgery. Written informed consent was obtained from patients and ethical approval was received from the Central Denmark Region Committee on Biomedical Research Ethics (Journal No 20030021). The study was registered at Clinical Trials.gov (NCT00119977).

All PAOs were performed by one surgeon (KS) using the transsartorial approach [24]. When performing the correction of the acetabulum, a specially made measuring device was used to measure the center-edge angle, using fluoroscopic guidance. This was done to avoid 
overcorrection of the acetabulum which can result in impingement [19].

The 26 study patients underwent MRI preoperatively; 25 patients were available for followup 1 year postoperatively which included another MRI series. Twenty-one patients were available for the 21/2-year followup, and $17(65 \%)$ underwent MRI at the 10-year postoperative followup. Of the nine who did not return for followups, three had undergone THA, three had substantial hip symptoms, and three were lost to followup. We compared baseline clinical and demographic data between the 17 who returned at 10 years with the nine who were lost to followup, and found that the 17 patients obtained a lower postoperative acetabular index angle $(\mathrm{p}=0.04)$ (Table 1).

Imaging examinations were performed on a 1.5 Tesla Scanner (MAGNETOM ${ }^{\circledR}$ Symphony $1.5 \mathrm{~T}$ eco; Siemens Corporation, Erlangen, Germany), using a body array surface coil. A fat-suppressed three-dimensional fast lowangle shot sequence was obtained. The imaging matrix was $256 \times 256$, and the field of view was $220 \times 220 \mathrm{~mm}$, with a section thickness of $1.5 \mathrm{~mm}$. The repetition/echo time (TR/TE) was $60.0 / 11.0 \mathrm{~ms}$, flip angle was $50^{\circ}$, and acquisition time was 9.38 minutes.

Continuous ankle traction was applied to the patient's leg during MRI to separate the acetabular and femoral cartilages. One person (IM) measured the thickness of the acetabular and femoral cartilage using a stereologic method we developed and which has been shown to be precise and efficient [15]. Based on repeated stereologic measurements of cartilage thickness obtained by preoperatively double MRI on 13 patients in this study, the limits of agreement are between -0.17 and $0.13 \mathrm{~mm}$ for acetabular cartilage and between -0.18 to $0.1 \mathrm{~mm}$ for femoral cartilage [15]. The stereologic method is based on four images through the center of the femoral head and was described in a previous study [16].

We used a design-based stereologic method (Cavalieri's principle) to measure the volume of cysts in the acetabulum and femoral head on sagittal images through the hip. The method was described previously [14]. All measurements were performed by one person (IM). Measurements of bone cysts, based on the same method, provided a limit of agreement between -1.45 and $2.01 \mathrm{~cm}$.

Ten years after surgery, the Hip dysfunction and Osteoarthritis Outcome Score (HOOS 2.0) questionnaire [20] was used to measure patient-reported outcome in the subscales symptoms, pain, activities of daily living, function in sport and recreation, and hip-related quality of life. HOOS ranges from 0 to 100 , with 100 equal to the best possible score. The HOOS scores were collected for all 17 patients when they came for MRI.

We present the results of the 17 patients who completed the 10-year-followup, and when pre- and postoperative comparisons were performed, only data from these 17 patients are compared. Data for cartilage thickness and cyst volume were tested for normality using the Shapiro-Wilk test and Q-Q plots. Normal distribution was assumed for cartilage thickness and differences between preoperative and 10-year postoperative data were tested by paired t test. Differences between preoperative cartilage thickness and radiographic angles in patients lost by the 10-year followup and the remainder of the patient group were tested using an unpaired t test. Data regarding cyst volume were not from a normal distribution and differences between preoperative and 10-year postoperative data were tested using Wilcoxon signed rank test. Stata ${ }^{\circledR}$ software, version 13.0 (StataCorp LP, College Station, TX, USA) was used for statistical computations.

\section{Results}

For the 17 patients who had MRI before surgery and 10 years later, the acetabular cartilage was unchanged 10 years after surgery compared with the preoperative acetabular cartilage thickness $(\mathrm{p}=0.73)$. Preoperatively, the mean thickness of the acetabular cartilage was $1.38 \pm 0.14 \mathrm{~mm}$; and 10 years postoperatively, it was $1.43 \pm 0.07 \mathrm{~mm}$ (Fig. 2). The patients' femoral cartilage was unchanged 10 years postoperatively compared with

Table 1. Baseline data for the 26 patients in the cohort

\begin{tabular}{|c|c|c|c|c|c|c|c|c|}
\hline Patients & $\begin{array}{l}\text { Age } \\
\text { (years) } \\
\text { Median } \\
\quad \text { (range) }\end{array}$ & $\begin{array}{l}\text { Sex, } \\
\text { females/ } \\
\text { males }\end{array}$ & $\begin{array}{l}\text { Preoperative } \\
\text { center-edge } \\
\text { angle } \\
\text { Mean (SD) }\end{array}$ & $\begin{array}{l}\text { Postoperative } \\
\text { center-edge } \\
\text { angle } \\
\text { Mean (SD) }\end{array}$ & $\begin{array}{l}\text { Preoperative } \\
\text { acetabular } \\
\text { index angle } \\
\text { Mean (SD) }\end{array}$ & $\begin{array}{l}\text { Postoperative } \\
\text { acetabular index } \\
\text { angle } \\
\text { Mean (SD) }\end{array}$ & $\begin{array}{l}\text { Preoperative } \\
\text { acetabular } \\
\text { cartilage thickness } \\
\text { Mean (SD) }\end{array}$ & $\begin{array}{l}\text { Preoperative } \\
\text { femoral cartilage } \\
\text { thickness } \\
\text { Mean (SD) }\end{array}$ \\
\hline $\begin{array}{l}\text { Completed } \\
\quad \text { followup } \\
(n=17)\end{array}$ & $43(19-53)$ & $16 / 1$ & $15^{\circ}\left(8^{\circ}\right)$ & $33^{\circ}\left(6^{\circ}\right)$ & $16^{\circ}\left(7^{\circ}\right)$ & $0.5^{\circ}\left(4^{\circ}\right)$ & $1.4 \mathrm{~mm}(0.1 \mathrm{~mm})$ & $1.3 \mathrm{~mm}(0.2 \mathrm{~mm})$ \\
\hline $\begin{array}{l}\text { Lost to } \\
\quad \text { followup } \\
(\mathrm{n}=9)\end{array}$ & $40(25-52)$ & $6 / 3$ & $9^{\circ}\left(15^{\circ}\right)$ & $29^{\circ}\left(7^{\circ}\right)$ & $21^{\circ}\left(10^{\circ}\right)$ & $4^{\circ}\left(5^{\circ}\right)$ & $1.5 \mathrm{~mm}(0.2 \mathrm{~mm})$ & $1.4 \mathrm{~mm}(0.2 \mathrm{~mm})$ \\
\hline
\end{tabular}




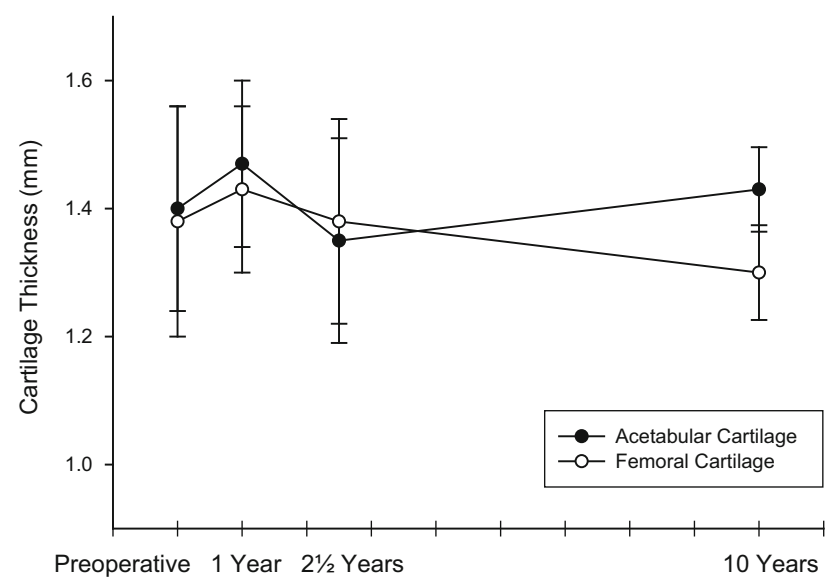

Fig. 2 Mean $( \pm S D)$ acetabular and femoral cartilage thicknesses of dysplastic hips estimated with MRI and stereology before and after periacetabular osteotomy are shown.

preoperatively $(\mathrm{p}=0.24)$. The mean thickness for the femoral cartilage preoperatively was $1.37 \pm 0.20 \mathrm{~mm}$ and at 10 years postoperatively, it was $1.30 \pm 0.07 \mathrm{~mm}$.

Among the 17 patients who had MRI before surgery and 10 years later, seven had an increase in cyst volume, six had a decrease, and four had no cysts to start with and remained without cysts (Table 2). All acetabular cysts were located anterolaterally in the acetabulum except one that was located posterolaterally. Femoral head cysts were positioned anterolaterally and anteromedially.

The volume of bone cysts was unchanged 10 years after PAO compared with volume before surgery $(\mathrm{p}=0.18)$. The median total cyst volume per patient preoperatively was $6.0 \mathrm{~cm}^{3}$ (range, $1.6-188.3 \mathrm{~cm}^{3}$ ) and 10 years postoperatively, it was $2.9 \mathrm{~cm}^{3}$ (range, $0.7-8.2 \mathrm{~cm}^{3}$ ). Preoperatively, three patients had cyst volumes greater than $80 \mathrm{~cm}^{3}$. Ten years later, outcomes for the same three patients were: one had undergone a THA, one had radiologically verified $\mathrm{OA}$, and one was lost to followup.

For the 17 patients who completed the 10-year MRI, self-assessed mean subscores for the HOOS were: pain, $79 \pm 16$; symptoms, $73 \pm 17$; activities of daily living, $85 \pm 14$; sport/recreation, $68 \pm 22$; and quality of life, $61 \pm 19$ (Table 2).

\section{Discussion}

Symptomatic patients with hip dysplasia undergo PAO to relieve pain, increase function, and hopefully, to delay or prevent the development of OA and the need for subsequent THA. It also is possible that the procedure may allow cartilage and bone repair [7], although the former has not been observed to our knowledge. We followed a cohort of patients for 10 years and investigated: (1) if changes in the thickness of hip cartilage take place after PAO; (2) how many of the studied patients had acetabular or femoral head cysts; (3) whether the volume of cysts changed after PAO; and (4) patient-reported hip function and pain after PAO.

We acknowledge limitations to our study. First, we had 10-year followup on only 17 of 26 study patients. There was no difference in preoperative cartilage thickness in patients who completed 10-year MRI and those who did not, but the 17 patients had a lower postoperative acetabular index angle after PAO (a less steep acetabulum) and tended to have less severe hip dysplasia with higher preoperative center-edge angle and lower preoperative acetabular index angle. From the electronic health records we collected information regarding the outcome of the nine patients not returning for the 10-year followup; three patients had THAs, three had hip symptoms, and three were lost to followup The three patients who underwent THAs most likely had thinner cartilage, lower HOOS scores, and possibly larger cyst volume at the time of revision compared with the preoperative measurements. One of the three patients with hip symptoms had verified hip OA and did not want a THA, one had labral degeneration treated with hip arthroscopy, and one had an injection of steroid and local anesthetic. Second, a limitation to our approach of measuring and presenting a mean cartilage thickness is that tissue loss in hip dysplasia is initiated in the anterolateral region [7] and the mean thickness may not show localized loss of cartilage. However, it has been shown with threedimensional delayed gadolinium-enhanced MRI that there are biochemical changes globally in dysplastic hips [4]. Although tissue degeneration may initiate locally, OA is a biologically mediated event that affects the entire joint. Finally, our sample size was small and therefore had low statistical power to detect changes.

Ten years after PAO, six patients (23\%) had substantial hip pain and/or had undergone THA and another three patients (12\%) were lost to followup. Among the 17 patients (65\%) who completed the 10-year MRI, cartilage thickness appeared to be preserved. Measurements of cartilage thickness represent radiographic joints space width or joint space narrowing [3,12], which is considered the reference standard for assessment of progression of hip OA. Jacobsen et al. [10] reported that joint space width less than $2 \mathrm{~mm}$ is associated with patient-reported pain in or around the hip, which is in line with the acceptable pain scores of the 17 patients who did not experience thinning of the cartilage during the 10-year period after PAO.

Among the 17 patients who had MRI before surgery and 10 years later, seven had an increase in cyst volume, six had a decrease, and four had no cysts to start with and remained without cysts. It is likely that cyst volume has increased in the six patients with hip pain or THA and the 
Table 2. Total cyst volume per patient (on MRI) and HOOS at followup

\begin{tabular}{|c|c|c|c|c|c|c|c|c|c|c|c|}
\hline \multicolumn{2}{|c|}{ Patients } & \multicolumn{4}{|c|}{ Total cyst volume per patient $\left(\mathrm{cm}^{3}\right)$} & \multicolumn{5}{|c|}{ HOOS at 10 years } & \multirow{2}{*}{$\begin{array}{l}\text { Outcomes }{ }^{\#} \text { for } 9 \text { patients } \\
\text { not attending } 10 \text {-year } \\
\text { followup }\end{array}$} \\
\hline $\begin{array}{l}\text { Age } \\
\text { at } \\
\text { PAO }\end{array}$ & Sex & Preoperative & $\begin{array}{l}1 \text { year } \\
\text { postoperative }\end{array}$ & $\begin{array}{l}21 / 2 \text { years } \\
\text { postoperative }\end{array}$ & $\begin{array}{l}10 \text { years } \\
\text { postoperative }\end{array}$ & Pain & Symptoms & $\mathrm{ADL}$ & $\begin{array}{l}\text { Sport/ } \\
\text { recreation }\end{array}$ & $\begin{array}{l}\text { Quality } \\
\text { of life }\end{array}$ & \\
\hline 41 & $\mathrm{~F}$ & 1.6 & 1.5 & 1.7 & None & 85 & 65 & 82 & 50 & 63 & \\
\hline 39 & $\mathrm{~F}$ & 2.9 & 1.9 & 2.1 & None & 58 & 70 & 82 & 69 & 63 & \\
\hline 47 & $\mathrm{~F}$ & 3.4 & 2.9 & 2.5 & * & $\sim$ & $\sim$ & $\sim$ & $\sim$ & $\sim$ & $\begin{array}{l}\text { Hip arthroscopy } 7 \text { years } \\
\text { after PAO }\end{array}$ \\
\hline 30 & $\mathrm{~F}$ & 18.2 & 2.1 & 13.2 & None & 98 & 90 & 100 & 100 & 81 & \\
\hline 47 & M & None & 8.5 & 7.0 & $*$ & $\sim$ & $\sim$ & $\sim$ & $\sim$ & $\sim$ & Lost to followup \\
\hline 52 & $\mathrm{~F}$ & 188.3 & 146.2 & 62.4 & $*$ & $\sim$ & $\sim$ & $\sim$ & $\sim$ & $\sim$ & $\begin{array}{l}\text { Hip OA but does not } \\
\text { want THA }\end{array}$ \\
\hline 47 & $\mathrm{~F}$ & 29.2 & 24.8 & 7.9 & 4.9 & 69 & 80 & 86 & 50 & 63 & \\
\hline 45 & $\mathrm{~F}$ & 1.9 & 0.6 & 2.6 & $*$ & $\sim$ & $\sim$ & $\sim$ & $\sim$ & $\sim$ & Lost to followup \\
\hline 25 & $\mathrm{~F}$ & 6.7 & 9.2 & $*$ & $*$ & $\sim$ & $\sim$ & $\sim$ & $\sim$ & $\sim$ & THA 8 years after PAO \\
\hline 53 & $\mathrm{~F}$ & 4.0 & 9.6 & 5.7 & 2.9 & 68 & 45 & 54 & 31 & 38 & \\
\hline 27 & M & None & 0.6 & 0.4 & $*$ & $\sim$ & $\sim$ & $\sim$ & $\sim$ & $\sim$ & THA 9 years after PAO \\
\hline 36 & M & 117.2 & 40.8 & 5.4 & $*$ & $\sim$ & $\sim$ & $\sim$ & $\sim$ & $\sim$ & Lost to followup \\
\hline 43 & $\mathrm{~F}$ & 5.4 & 6.6 & 4.2 & None & 90 & 75 & 97 & 75 & 63 & \\
\hline 27 & $\mathrm{~F}$ & None & 10.9 & 2.9 & None & 73 & 55 & 82 & 75 & 81 & \\
\hline 37 & $\mathrm{~F}$ & 80.6 & 68.8 & 13.1 & $*$ & $\sim$ & $\sim$ & $\sim$ & $\sim$ & $\sim$ & THA 4 years after PAO \\
\hline 44 & $\mathrm{~F}$ & None & None & $*$ & 3.5 & 70 & 60 & 78 & 44 & 63 & \\
\hline 52 & $\mathrm{~F}$ & None & None & None & 2.7 & 80 & 90 & 94 & 56 & 88 & \\
\hline 47 & $\mathrm{~F}$ & None & None & None & 0.7 & 98 & 95 & 90 & 63 & 75 & \\
\hline 32 & $\mathrm{~F}$ & None & None & None & 8.3 & 80 & 75 & 91 & 88 & 38 & \\
\hline 44 & $\mathrm{~F}$ & None & None & $*$ & 2.3 & 100 & 80 & 100 & 100 & 81 & \\
\hline 30 & $\mathrm{~F}$ & None & None & None & 7.4 & 53 & 60 & 79 & 44 & 31 & \\
\hline 48 & M & None & None & None & 1.9 & 93 & 85 & 88 & 88 & 63 & \\
\hline 19 & $\mathrm{~F}$ & None & None & None & None & 88 & 95 & 100 & 88 & 56 & \\
\hline 29 & $\mathrm{~F}$ & None & None & None & None & 50 & 35 & 53 & 44 & 19 & \\
\hline 40 & $\mathrm{~F}$ & None & None & $*$ & $*$ & $\sim$ & $\sim$ & $\sim$ & $\sim$ & $\sim$ & $\begin{array}{l}\text { Hip injection of steroid/ } \\
\text { local anesthetic }\end{array}$ \\
\hline 52 & $\mathrm{~F}$ & None & $*$ & $*$ & None & 98 & 80 & 96 & 94 & 81 & \\
\hline
\end{tabular}

PAO = periacetabular osteotomy; HOOS = Hip disability and Osteoarthritis Outcome Score; ADL = activities of daily living; OA = osteoarthritis; *did not attend MRI; did not complete HOOS at 10-year followup; ${ }^{\#}$ from the electronic health record.

three lost to followup. In a worst-case scenario we have a preponderance of worsening with time. As for the $17 \mathrm{pa}-$ tients completing 10-year MRI, volume of subchondral bone cysts was unchanged 10 years after PAO. However, the number of patients with an acetabular or femoral head cyst before PAO was low and we encourage caution with any interpretations. Since six patients had a decrease in cyst volume, a regenerative process can take place in the bony tissue after PAO where the biomechanical loading on the hip changes $[2,11]$. In our study, this was supported by all bone cysts except two being located anterolaterally in the hip, where degeneration in the dysplastic hip often is found [7] and where peak contact stress is localized [21, 27]. Nakamura et al. [18] also found partial or complete cyst remodeling in 17 of 21 hips 5 years after patients underwent PAO. However, to our knowledge, cyst remodeling after PAO has not been reported in the literature, other than by Nakamura et al.

For the 17 patients without failed PAO, the patient-reported HOOS scores indicate acceptable hip function and pain up to 10 years after the procedure. The presence of bone cysts did not directly influence patient-reported hip function and pain. Patients with cysts did not score lower than those with no cysts on the HOOS assessments. Two patients had generally low HOOS scores but neither had bone cysts. Different patient-reported outcome scores are used to describe the mid- to long-term clinical outcomes after PAO and therefore are not directly comparable to the 
HOOS scores applied in our study, but our scores are in a similar range of acceptable scores for pain, function, and quality of life as reported by others [1, 13, 22, 23].

Ten years after PAO, approximately $25 \%$ of the patients having a PAO will have substantial hip pain and/or undergo an arthroplasty. Of the patients who do not, cartilage thickness appears to be preserved. Future studies will need to help us decide which patients are most likely to succeed with a PAO at long-term followup.

\section{References}

1. Albers CE, Steppacher SD, Ganz R, Tannast M, Siebenrock KA. Impingement adversely affects 10 -year survivorship after periacetabular osteotomy for DDH. Clin Orthop Relat Res. 2013;471:1602-1614.

2. Armiger RS, Armand M, Tallroth K, Lepisto J, Mears SC. Threedimensional mechanical evaluation of joint contact pressure in 12 periacetabular osteotomy patients with 10-year follow-up. Acta Orthop. 2009;80:155-161.

3. Bloecker K, Wirth W, Hunter DJ, Duryea J, Guermazi A, Kwoh CK, Resch H, Eckstein F. Contribution of regional 3D meniscus and cartilage morphometry by MRI to joint space width in fixed flexion knee radiography: a between-knee comparison in subjects with unilateral joint space narrowing. Eur J Radiol. 2013;12: e832-839.

4. Hingsammer A, Chan J, Kalish LA, Mamisch TC, Kim YJ. Is the damage of cartilage a global or localized phenomenon in hip dysplasia, measured by dGEMRIC? Clin Orthop Relat Res. 2013;471:301-307.

5. Jacobsen JS, Nielsen DB, Sorensen H, Soballe K, Mechlenburg I. Changes in walking and running in patients with hip dysplasia. Acta Orthop. 2013;84:265-270.

6. Jacobsen JS, Nielsen DB, Sorensen H, Soballe K, Mechlenburg I. Joint kinematics and kinetics during walking and running in 32 patients with hip dysplasia 1 year after periacetabular osteotomy. Acta Orthop. 2014:85:592-599.

7. Jacobsen S, Romer L, Soballe K. Degeneration in dysplastic hips: a computer tomography study. Skeletal Radiol. 2005;34:778-784.

8. Jacobsen S, Sonne-Holm S, Soballe K, Gebuhr P, Lund B. Radiographic case definitions and prevalence of osteoarthrosis of the hip: a survey of 4151 subjects in the Osteoarthritis Substudy of the Copenhagen City Heart Study. Acta Orthop Scand. 2004;75:713720.

9. Jacobsen S, Sonne-Holm S, Soballe K, Gebuhr P, Lund B. The distribution and inter-relationships of radiologic features of osteoarthrosis of the hip: a survey of 4151 subjects of the Copenhagen City Heart Study: the Osteoarthrosis Substudy. Osteoarthritis Cartilage. 2004;12:704-710.

10. Jacobsen S, Sonne-Holm S, Soballe K, Gebuhr P, Lund B. The relationship of hip joint space to self reported hip pain: a survey of 4,151 subjects of the Copenhagen City Heart Study: the Osteoarthritis Substudy. Osteoarthritis Cartilage. 2004;12:692-697.

11. Kralj M, Mavcic B, Antolic V, Iglic A, Kralj-Iglic V. The Bernese periacetabular osteotomy: clinical, radiographic and mechanical 7-15-year follow-up of 26 hips. Acta Orthop. 2005;76:833-840.

12. Mandl P, Supp G, Baksa G, Radner H, Studenic P, Gyebnar J, Kurucz R, Niedermayer D, Aletaha D, Balint PV, Smolen JS. Relationship between radiographic joint space narrowing, sonographic cartilage thickness and anatomy in rheumatoid arthritis and control joints. Ann Rheum Dis. 2014 June 24. [Epub ahead of print].

13. Matheney T, Kim YJ, Zurakowski D, Matero C, Millis M. Intermediate to long-term results following the Bernese periacetabular osteotomy and predictors of clinical outcome. $J$ Bone Joint Surg Am. 2009;91:2113-2123.

14. Mechlenburg I, Nyengaard JR, Gelineck J, De Raedt S, Soballe $K$. Cyst volume in the acetabulum and femoral head decreases after periacetabular osteotomy. Hip Int. 2012;22:313-318.

15. Mechlenburg I, Nyengaard JR, Gelineck J, Soballe K. Cartilage thickness in the hip joint measured by MRI and stereology: a methodological study. Osteoarthritis Cartilage. 2007;15:366371.

16. Mechlenburg I, Nyengaard JR, Gelineck J, Soballe K, Troelsen A. Cartilage thickness in the hip measured by MRI and stereology before and after periacetabular osteotomy. Clin Orthop Relat Res. 2010;468:1884-1890.

17. Mechlenburg I, Nyengaard JR, Romer L, Soballe K. Prospective bone density changes after periacetabular osteotomy: a methodological study. Int Orthop. 2005;29:281-286.

18. Nakamura Y, Naito M, Akiyoshi Y, Shitama T. Acetabular cysts heal after successful periacetabular osteotomy. Clin Orthop Relat Res. 2007;454:120-126.

19. Nassif NA, Schoenecker PL, Thorsness R, Clohisy JC. Periacetabular osteotomy and combined femoral head-neck junction osteochondroplasty: a minimum two-year follow-up cohort study. J Bone Joint Surg Am. 2012;94:1959-1966.

20. Nilsdotter AK, Lohmander LS, Klassbo M, Roos EM. Hip disability and osteoarthritis outcome score (HOOS): validity and responsiveness in total hip replacement. BMC Musculoskelet Disord. 2003;4:10.

21. Nishii T, Shiomi T, Tanaka H, Yamazaki Y, Murase K, Sugano $\mathrm{N}$. Loaded cartilage T2 mapping in patients with hip dysplasia. Radiology. 2010; 256:955-965.

22. Polkowski GG, Novais EN, Kim YJ, Millis MB, Schoenecker PL, Clohisy JC. Does previous reconstructive surgery influence functional improvement and deformity correction after periacetabular osteotomy? Clin Orthop Relat Res. 2012;470:516-524.

23. Steppacher SD, Tannast M, Ganz R, Siebenrock KA. Mean 20year followup of Bernese periacetabular osteotomy. Clin Orthop Relat Res. 2008;466:1633-1644.

24. Troelsen A, Elmengaard B, Soballe K. A new minimally invasive transsartorial approach for periacetabular osteotomy. J Bone Joint Surg Am. 2008;90:493-498.

25. Tönnis D. Congenital Dysplasia and Dislocation of the Hip in Children and Adults. Berlin, Germany: Springer; 1987.

26. Wiberg G. Studies on dysplastic acetabula and congenital subluxation of the hip joint. Acta Orthop Scand Suppl. 1939;58:2838.

27. Zhao X, Chosa E, Totoribe K, Deng G. Effect of periacetabular osteotomy for acetabular dysplasia clarified by three-dimensional finite element analysis. J Orthop Sci. 2010;15:632-640. 